\title{
Anatomical Variants of Anterior Cerebral Arterial Circle. A Study by Multidetector Computerized 3D Tomographic Angiography
}

\author{
Variantes Anatómicas de la Región Anterior del Circulo Arterial \\ Cerebral. Estudio por Angiotomografía Computarizada 3D
}

\begin{abstract}
Michelle Stephanie Jiménez-Sosa ${ }^{1}$; Juan Ramón Cantu-Gonzalez²; Rodolfo Morales-Avalos ${ }^{1}$; Oscar de la Garza-Castro ${ }^{1}$; Alejandro Quiroga-Garza ${ }^{1}$; Ricardo Pinales-Razo²; Guillermo Elizondo-Riojas²; Rodrigo E. Elizondo-Omaña ${ }^{1}$; Santos Guzmán- López ${ }^{1}$
\end{abstract}

JIMÉNEZ-SOSA, M. S.; CANTU-GONZALEZ, J. R.; MORALES-AVALOS, R.; GARZA-CASTRO, O.; QUIROGA-GARZA, A.; PINALES-RAZO, R.; ELIZONDO-RIOJAS, G.; ELIZONDO-OMAÑA, R. E. \& GUZMÁN-LÓPEZ, S. Anatomical variants of anterior cerebral arterial circle. A study by multidetector computerized 3d tomographic angiography. Int. J. Morphol., 35(3):11211128, 2017.

SUMMARY: One of the most common causes of stroke is rupture of aneurysms whose approach requires knowledge of anatomical variants. The aim of this study was to determine the prevalence of anatomical variants of the anterior cerebral artery (ACA) and the anterior communicating artery (AComA) by 3D computed tomography angiography (3D CTA) in Mexican individuals. A retrospective, observational, cross-sectional descriptive study of 283 patients, independent of sex or age, in which morphometric measurements of cerebral vessels were evaluated using contrasted 3D CTA from a period of two years was performed. We found at least one "atypical" variant in a third of the study population (33.93\%). The most common "atypical" variant was the absence of the AComA (14.1\%). A significant association between the hypoplastic variant of the right A1 segment and hypoplasia of the left A1 and the right A2 was found, while hypoplasia of the left A1 was associated with hypoplasia of the right A2. There is a difference in the prevalence of anatomical variants of the ACA-AComA complex in Mexican population in relation to other populations. The typical variant is the most prevalent form in the study population. However, the presence of atypical variants represents an important number that should be taken into account in clinical and surgical procedures.

KEY WORDS: Anterior cerebral artery; Anatomical variant; Anterior communicating artery; Cerebral arterial circle; Subarachnoid hemorrhage; Cerebral endovascular surgery.

\section{INTRODUCTION}

Stroke is the second leading cause of death worldwide and the leading cause of disability in developed countries according to the World Health Organization (WHO, 2017). In Mexico, it represents the sixth leading cause of death (INEGI, 2015). The most common cause of stroke is subarachnoid hemorrhage $(\mathrm{SAH})$ due to rupture of intracranial aneurysms (21-76 \%), (Lu et al., 2013). Their most frequent location is the anterior cerebral artery (ACA)anterior communicating artery (AComA) complex (MonroySosa et al., 2013). Aneurysms located in the ACA and AComA are difficult to manage and have a poor prognosis due to angioarchitecture, blood flow, their deep location in the brain, and little known anatomical variants. It is estimated that the lack of knowledge of these variants are the cause of approximately $10 \%$ of medical errors. The anterior area of the cerebral arterial circle is the most variable site anatomically (Makowicz et al., 2013).

The anatomical variants of the cerebral arterial circle have been described in cadaveric studies by digital subtraction angiography (DSA), magnetic resonance angiography (MRA) and computed tomographic angiography (CTA). However, most have limitations due to small sample size, not making morphometric measurements of vessels, not including all the variants described in the literature; also, the postcommunicating segment (A2) of the ACA, whose anatomy influences the flow dynamics of the cerebral arterial circle is rarely studied. Some studies do not describe specific variants of the anterior communicating artery and group them as "fenestrations of the AComA",

\footnotetext{
${ }^{1}$ Universidad Autónoma de Nuevo León, Facultad de Medicina, Departamento de Anatomía Humana, Monterrey, Nuevo León, México.

${ }^{2}$ Universidad Autónoma de Nuevo León, Facultad de Medicina, Hospital Universitario “Dr. José Eleuterio González” Departamento de Radiología e Imagen, Monterrey, Nuevo León, Mexico.
} 
JIMÉNEZ-SOSA, M. S.; CANTU-GONZALEZ, J. R.; MORALES-AVALOS, R.; GARZA-CASTRO, O.; QUIROGA-GARZA, A.; PINALES-RAZO, R.; ELIZONDO-RIOJAS, G.; ELIZONDO-OMAÑA, R. E. \& GUZMÁN-LÓPEZ, S. Anatomical variants of anterior cerebral arterial circle. A study by multidetector computerized $3 \mathrm{~d}$ tomographic angiography. Int. J. Morphol., 35(3):1121-1128, 2017

which limits the anatomical knowledge of this vessel (Kayembe et al., 1984; Dimmick \& Faulder, 2009; Ferré et al., 2013; Hashemi et al., 2013; Iqbal, 2013; Kardile et al., 2013; Kedia et al., 2013).

In Mexico there are two previous studies that describe anatomical variants of the cerebral arterial circle, one in cadavers and another with MRA (Monroy-Sosa et al.). However, it is not possible to extrapolate these results in patients because of certain limitations in the methodology (Boleaga-Durán et al., 2004; Li et al., 2011). Moreover, CTA is the current method for initial assessment of cerebral circulation in suspected acute stroke or subarachnoid hemorrhage and the technique of choice for the evaluation of aneurysms (Zhang et al., 2012; Cirillo et al., 2013). We have not found studies using CTA in Mexican population.

The aim of this study was to determine the prevalence and morphometric characteristics of anatomical variants of the AComA and the precommunicating (A1) and postcommunicating (A2) segments of the anterior cerebral artery by cerebral computerized angiotomography with 3D reconstruction (3D CTA).

\section{MATERIAL AND METHOD}

A retrospective, observational, cross-sectional descriptive study performed at the Department of Human Anatomy and the Department of Radiology, of our institution. CTA images with three-dimensional reconstruction from 283 patients were evaluated. These were obtained during a period of 24 months (January 2013-December 2014) and included 156 men and 127 women distributed by sex and age groups.

Angiotomography scans of patients 1 to 99 years of age were included. The indications for these studies were: head trauma, headache refractory to treatment, and suspected hemorrhagic vascular or neoplastic disease. Patients with surgical clips causing metal artifacts, intracerebral hematoma, a tumor, previous surgery or any space-occupying lesion that involves or modify the anatomy of the cerebral arterial circulation were excluded.

The images were obtained using a 64-slice CT scanner (General Electric CT99 Light Speed VCT) with Software $2978195 \mathrm{VCT}$, using the following parameters: $0.4 \mathrm{~s}$ rotation of helical acquisition, $20 \mathrm{~mm}$ detector coverage, 120 $\mathrm{Kv}, 400 \mathrm{mAs}$, slice thickness $0.625 \mathrm{~mm}$, Pitch 0.53:1 mm/ rot and FOV of 22 to $23 \mathrm{~cm}$. All patients were injected with an intravenous iodinated contrast media (Ultravist 370, Bayer, Germany) at a dose of 1 to $2 \mathrm{ml}$ per $\mathrm{kg}$ with an injection rate of $4 \mathrm{ml}$ per second. The data obtained were transferred and analyzed in a workstation (AW Volume Share 2 workstation) using multiplanar reformatting (MPR) with maximum intensity projection (MIP) and volume rendering (VR). Measures were made using a window range of WW:350 standardized for all patients with General Electric ADW 4.4 software at the midpoint of each evaluated vessel.

The arteries studied were the anterior communicating and the A1 (precommunicating) and A2 (postcommunicating) segments of the anterior cerebral artery. The segment which originates from the internal carotid artery to the origin of the anterior communicating artery was defined as segment A1 and the segment that originates from the AComA to the site proximal to its bifurcation in the pericallosal and callosomarginal arteries was defined as segment A2 (Krzyz ewski et al., 2015).

Vascular variants were classified according to the classification of Kayembe et al., with some modifications suggested by our working group, which are shown in Figure 1 .

- Variants of the anterior communicating artery-V-shaped, Y-shaped, H-shaped, N-shaped, X-shaped, double, triple, plexiform and absent.

- Variants of the A1 and A2 segments of the anterior cerebral artery: absence, hypoplasia and fenestration.

- Other variants: triple ACA, and azygos.

- "Normal or typical" variant of the ACA-AComA according to the description by Rhoton (2002).

The internal diameter measurement of the midpoint of the bilateral A1, A2 segments of the anterior cerebral artery, the azygos artery and the accessory of the anterior cerebral artery (ACAacs) in the case of the triple variant of the ACA was performed. Hypoplastic segments were considered when size was less than $1 \mathrm{~mm}$ (Monroy-Sosa et al.).

Statistical analysis. A database was created in SPSS version 20.0 (IBM, Inc., Chicago, IL) for Windows XP. The relative frequencies and percentages of each anatomical variant studied according to sex and age group were obtained. Similarly, nonparametric correlation tests (chi square) were used to determine the association between sex and anatomical variants.

Ethical considerations. This protocol was approved by the Ethics and Research Committees of the institution of origin, registration number AH14-001. There are no financial or commercial gains for the realization of this study therefore the authors declare that they have no conflict of interest. 


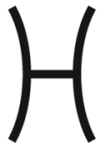

Typical

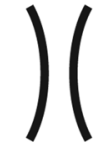

Absence

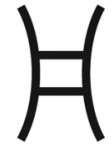

Double

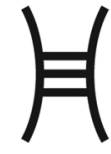

Triple

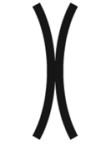

X-shaped

AcomA

ACA A1

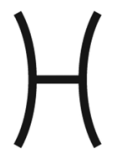

Typical

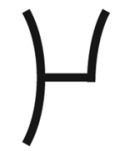

Absence

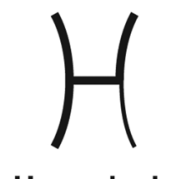

Hypoplasia

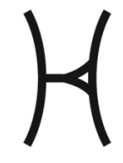

Y-shaped

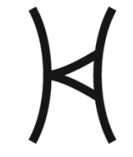

V-shaped
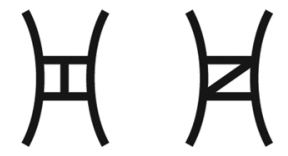

$\mathrm{H}$-shaped $\mathrm{N}$-shaped

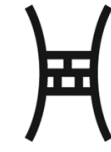

Plexiform
ACA A2

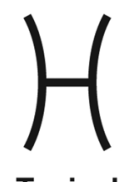

Typical

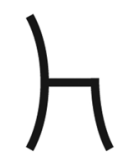

Absence

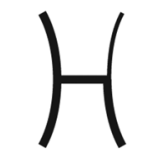

Hypoplasia

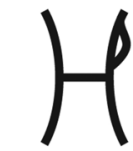

Fenestration

Other Variants

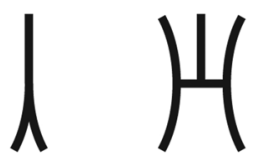

Azigos Triple ACA

Fig. 1. Classification of anatomical variants of the A1 and A2 segments of the anterior cerebral artery (ACA) and the anterior communicating artery (AComA). Modification of Kayembe, Sasahara, and Hazam Classification. Krzyzewski et al., 2015

\section{RESULTS}

A total of 283 computerized angiotomography scans, from 127 female and 156 male patients were analyzed; mean age was $50 \pm 18$ years. The most prevalent anatomical variant was the typical form of the ACA-AComA complex in 66.07 $\%$ (Fig. 2a.) and one-third of the CTA scans showed at least one different anatomical variant of these $(33.93 \%)$. No variant showed a significant association with sex or age.

Anterior communicating artery. The typical form of this vessel was found in $81.99 \%$ of the population. The rest (18 $\%)$ of the atypical variants corresponded to the absence of AComA (14.13\%) (Fig. 2b), type X (3.18\%), double (0.35 $\%)$, and triple AComA (0.35\%). No V-, Y-, H- or N-shaped variants were found. There was no significant association with any variant of the AComA and any other anatomical variant in the anterior circulation of the cerebral arterial circle in the same patient.

A1 segment of the anterior cerebral artery. The typical A1 variant was found in $86.93 \%$. Of the atypical variants, 51.35 $\%$ were located in the right $\mathrm{A} 1$ and $48.64 \%$ in the left $\mathrm{A} 1$. Atypical variants in order of frequency were: absence (5.65 $\%$ ) (Fig. 2c.), hypoplasia (5.30\%) and fenestration (2.12\%).
The mean diameter found in right $\mathrm{A} 1$ and left $\mathrm{A} 1$ was $1.9 \pm$ $0.5 \mathrm{~mm}$. The hypoplastic right A1 variant was associated with the hypoplastic left A1 ( $\mathrm{p}<0.0001)$ and a hypoplastic right A2 $(p=0.002)$, with statistical significance. In some cases, the presence of a hypoplastic right A1 with a hypoplastic left A2 $(n=4)$ or a triple ACA variant $(n=1)$ was observed but with no significant association ( $p>0.05$ ). A hypoplastic left A1 variant was associated with a hypoplastic right A2 (p $<0.0001)$ and a hypoplastic left A2 ( $\mathrm{p}=0.15)$.

A2 segment of the anterior cerebral artery. The typical variant of the postcommunicating anterior cerebral artery A2 segment was found in $95.40 \%$ of the angiotomographies studied. Of all atypical variants, $53.85 \%$ were located in the right A2 and $46.15 \%$ in the left A2. Atypical variants were: hypoplasia $(4.25 \%)$ and absence $(0.35 \%)$, no fenestrations were found. The mean diameter was the same in the right and left A2 segments, $1.9 \pm 0.5 \mathrm{~mm}$. The hypoplastic right $\mathrm{A} 2$ was associated with the hypoplastic left A2 ( $\mathrm{p}<0.0001)$.

Other variants found in the anterior cerebral artery was the azygos variant (Fig. 2e), which was found in 5 


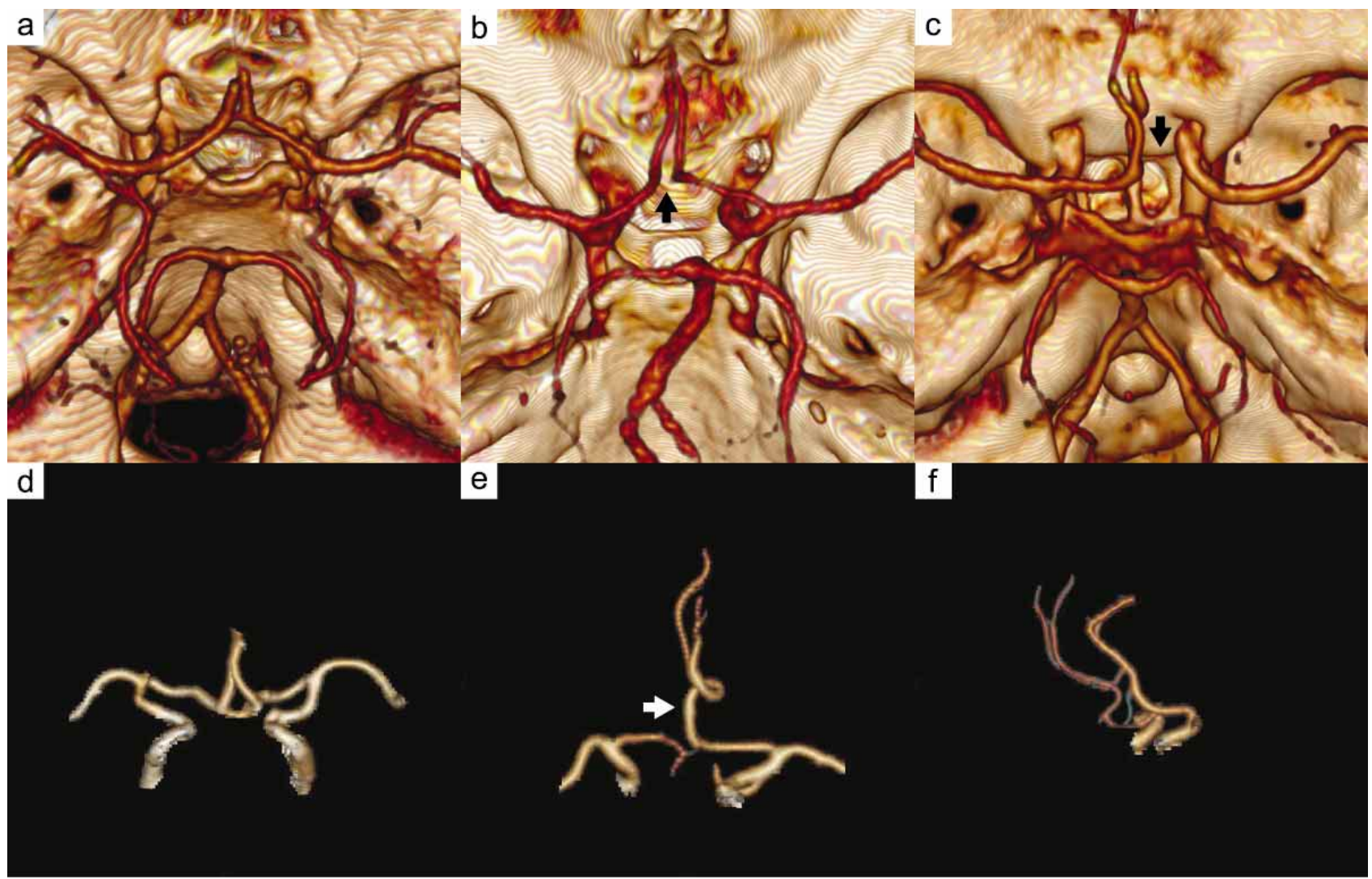

Fig. 2. Images obtained by computed tomography with 3D reconstruction in different patients that show anatomical variants found in the circle of Willis (arrows). A) and D) "Typical" variant of the anterior cerebral artery-anterior communicating artery; B) Absence of the AComA; C) Absence of the right precommunicating A1 segment of the anterior cerebral artery; E) Azygos artery, F) triple variant of the ACA.

patients $(1.76 \%)$ and the triple ACA found in $11(3.88 \%)$ (Fig. 2f). The mean diameter of the azygos artery was $2.7 \pm$ $0.5 \mathrm{~mm}$ and the anterior cerebral artery accessory had a mean diameter of $1.4 \pm 2.0 \mathrm{~mm}$. There was no significant association between the presence of the azygos or the triple ACA artery with other variants.

Aneurysms. Ten aneurysms were found, all with secular morphology. Ten percent were located in the right A2 segment, $30 \%$ in the left A2, $20 \%$ at the junction of the A1 with the AComA (significantly associated with an absence of the right $\mathrm{A} 1, \mathrm{p}=0.008), 10 \%$ were in the azygos artery and $30 \%$ in the $\mathrm{AComA}$ (one associated with the absence of right $\mathrm{A} 1, \mathrm{p}=$ 0.008 , one with the absence of a left A1, p $=0.853$, and the last with hypoplasia of the right $\mathrm{A} 2, \mathrm{p}=0.156$ ). The mean diameter found in the neck of the aneurysm was $0.5 \pm 0.1$ $\mathrm{mm}$, and the largest diameter of the aneurysmal sac was $0.2 \pm$ $0.9 \mathrm{~mm}$. Eighty percent occurred in men with no significant association ( $p=0.501)$; also, no association was found with age. A tendency of aneurysms to appear with smaller diameters of the right A2 segment of the ACA $(p=0.039)$ was found.

\section{DISCUSSION}

The most important result of this study was that one third $(33.93 \%)$ of the study population presented atypical variants. This is important because some variants are associated with an increased risk of ischemic events and/or aneurysm formation (Makowicz et al.).

Our study is the first to use 3D CTA to report the prevalence of anatomic variants of the anterior cerebral artery and the anterior communicating artery in Mexican population. All anatomical variants that have been described so far in the literature have been included, and the precommunicating (A1) postcommunicating (A2) segments of the anterior cerebral artery were analyzed. The variants in the A2 segment have been little studied so far in the literature compared to the rest of the vessels.

This study is important because it reports the anatomical variants of Mexican population using a highly 
JIMÉNEZ-SOSA, M. S.; CANTU-GONZALEZ, J. R.; MORALES-AVALOS, R.; GARZA-CASTRO, O.; QUIROGA-GARZA, A.; PINALES-RAZO, R.; ELIZONDO-RIOJAS, G.; ELIZONDO-OMAÑA, R. E. \& GUZMÁN-LÓPEZ, S. Anatomical variants of anterior cerebral arterial circle. A study by multidetector computerized $3 \mathrm{~d}$ tomographic angiography. Int. J. Morphol., 35(3):1121-1128, 2017.

sensitive and specific method (Dimmick \& Faulder; Makowicz et al., 2013). The presence of anatomic variants characterized by the lack of collateral circulation increase the risk of ischemic events and a correlation between some anatomical variants of the cerebral arterial circle and the development of aneurysms has been established (Dimmick \& Faulder; Li et al.; KlimekPiotrowska et al., 2013; Yi et al., 2016). The information about the variants could be useful to the surgeon for better diagnostic and therapeutic planning.

Previous studies have found a significant difference in the prevalence of anatomical variants of the cerebral arterial circle among different ethnic groups (De Silva et al., 2009; KlimekPiotrowska et al.). The prevailing anatomical variant in most studies has been the typical form of the anterior cerebral artery- anterior communicating artery complex with a range between 14.2-76.25\%. In our study, we obtained a total prevalence of $66.07 \%$ for this variant, showing results superior to those obtained in populations such as Poland, Japan, India and Sri Lanka (De Silva et al.; Iqbal; Kardile et al.; Kayembe et al.; Klimek-Piotrowska et al.; Krzyz ewski et al.). However, studies in Serbia and China had a greater prevalence than ours with $73.20 \%$ and $76.25 \%$, respectively ( $\mathrm{Li}$ et al.; Stojanovic' et al., 2015) (Tables I and II).

Cadaveric studies reported as the most prevalent atypical variants: the double anterior communicating artery (India, 10-33.33\%), fenestration of the anterior communicating artery (Japan, $29.9 \%$ ), hypoplastic precommunicating A1 segment (Serbia, $16 \%$ ) and the $\mathrm{X}$-shape of the anterior communicating artery (Sri Lanka, 23 \%) (Kayembe et al.; De Silva et al.; Iqbal; Kardile et al.; Kedia et al.; Stojanovic' et al.). In imaging studies, the most prevalent atypical variants were: absence of the anterior communicating artery (Poland, $19.71 \%$ and $22.8 \%$ ), and hypoplasia of the precommunicating A1 segment artery (China, Australia and Serbia, 10-17.6\%) These results are similar to our study and Boleaga-Durán et al. who found hypoplasia of the precommunicating A1 segment as the most prevalent atypical variant with $9.6 \%$, while we found the absence of AComA (14.13\%) (Boleaga-Durán et al.; Klimek-Piotrowska et al.; Li et al.; Kovac ${ }^{\imath}$ et al., 2014; Krzyz' ewski et al.). The difference between
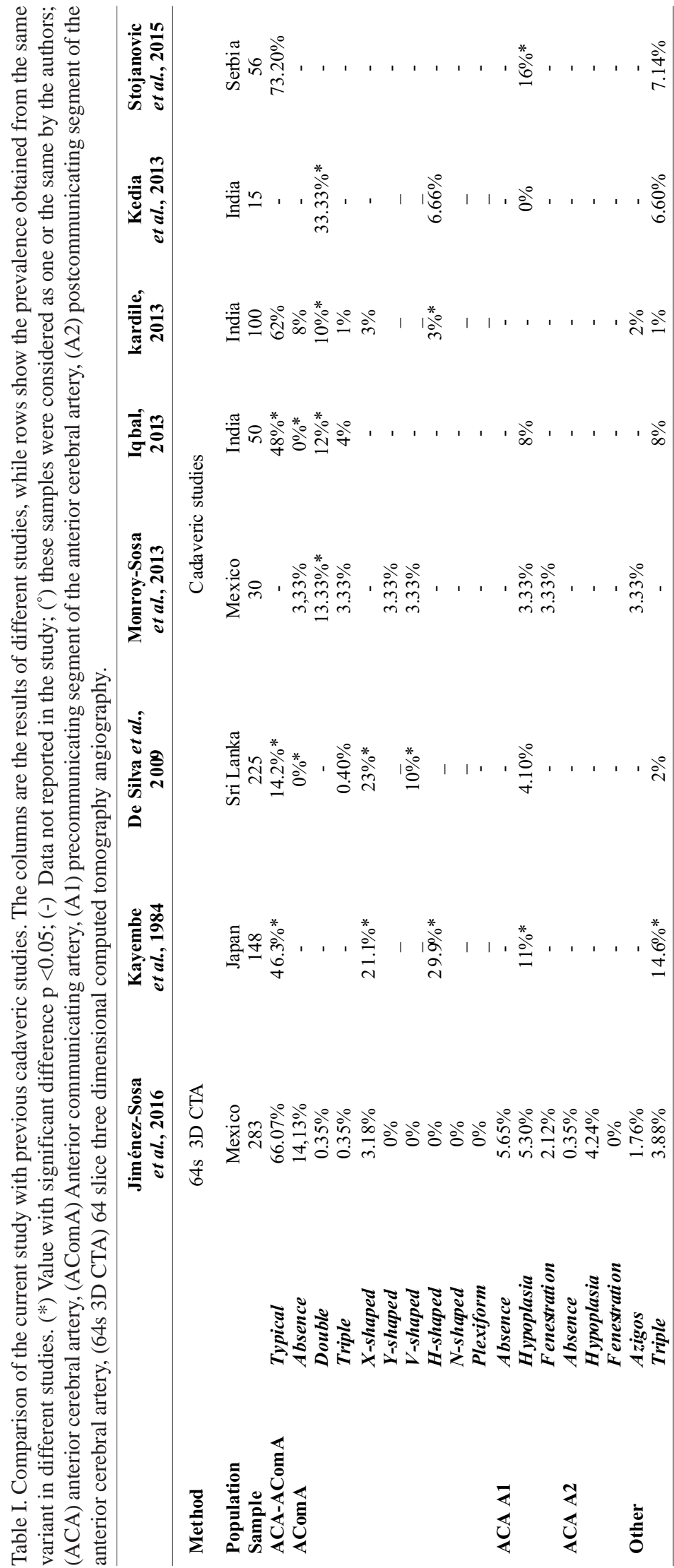
to
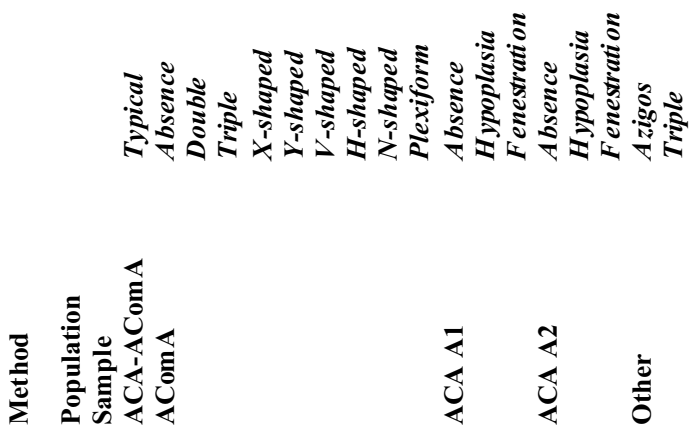
JIMÉNEZ-SOSA, M. S.; CANTU-GONZALEZ, J. R.; MORALES-AVALOS, R.; GARZA-CASTRO, O; QUIROGA-GARZA, A.; PINALES-RAZO, R.; ELIZONDO-RIOJAS, G.; ELIZONDO-OMAÑA, R. E. \& GUZMÁN-LÓPEZ, S. Anatomical variants of anterior cerebral arterial circle. A study by multidetector computerized $3 \mathrm{~d}$ tomographic angiography. Int. J. Morphol., 35(3):1121-1128, 2017

cadaveric and imaging studies is that in cadaveric studies the most prevalent variants were located in the anterior communicating artery, which is the smallest vessel we studied in the anterior circulation of the cerebral arterial circle, and in imaging studies, the absence of this same vessel prevailed. These differences could be attributed to a lower sensitivity of imaging studies for detecting anatomical variants of small and hypoplastic vessels such as the AComA, indicating that if this vessel is not seen it does not necessarily mean it is not present; however, it has been described that CTA has a high sensitivity and specificity in detecting absence and in measurement of the arterial segments of the cerebral arterial circle (Han et al., 2011) (Table I and II).

Few studies have evaluated the variants of fenestration (X-, Y-, V-, H- and N-shaped) of the anterior communicating artery of which none were found in our population. Anatomical and imaging studies that show the prevalence of these anatomical variants are needed.

In Mexico, there are two studies of the anatomical variants of the cerebral arterial circle. Monroy-Sosa et al. studied the A1 segment of the anterior cerebral artery and the anterior communicating artery in 30 brains. La double anterior communicating artery was the most prevalent variant in $13.3 \%$ compared to $0.35 \%$ in our study. Other variants found obtained a percentage of $3.33 \%$. The mean diameters obtained of the right and left A1 segment were similar to those obtained in our study. Most of the results obtained by Monroy-Sosa et al., showed differences with ours; however, the sample size is an important limitation of this study and their results do not indicate the absolute behavior of the anatomical variants. Moreover, the absence of blood perfusion pressure, the possible contraction of the vascular wall in individuals postmortem, latex infiltration, and fixation with formaldehyde prior to vascular measurements could alter the diameters obtained by cadaveric methods ( $\mathrm{Li}$ et al.; Iqbal).

Another study in Mexican population used cerebral 3D time of flight magnetic resonance angiography (MRA 3D TOF) to describe the anatomical variants of the cerebral arterial circle, showing a lower prevalence of variants in the an-
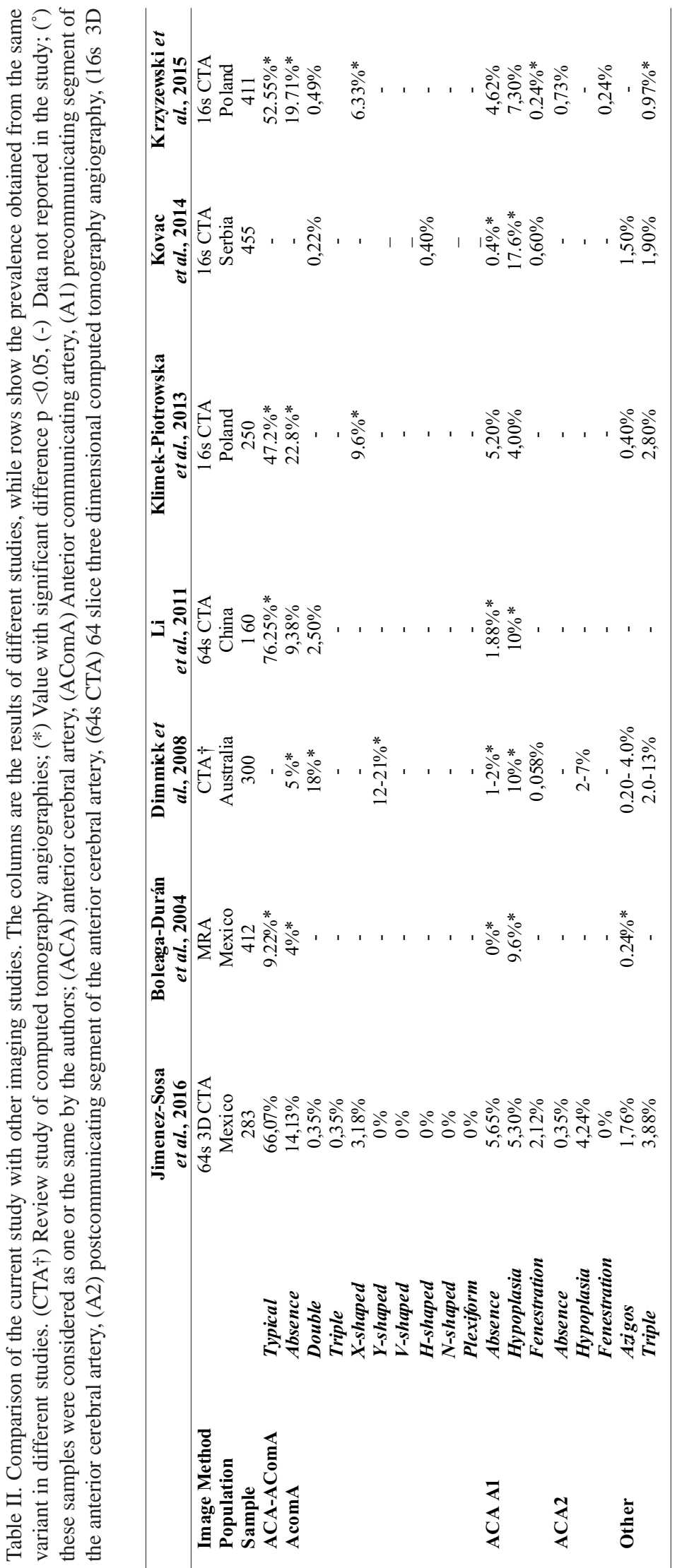
JIMÉNEZ-SOSA, M. S.; CANTU-GONZALEZ, J. R.; MORALES-AVALOS, R.; GARZA-CASTRO, O.; QUIROGA-GARZA, A.; PINALES-RAZO, R.; ELIZONDO-RIOJAS, G.; ELIZONDO-OMAÑA, R. E. \& GUZMÁN-LÓPEZ, S. Anatomical variants of anterior cerebral arterial circle. A study by multidetector computerized $3 \mathrm{~d}$ tomographic angiography. Int. J. Morphol., 35(3):1121-1128, 2017.

terior region of the cerebral arterial circle in comparison to that obtained in our study (Boleaga-Durán et al.). The typical form was present in $9.22 \%$, a low percentage in comparison with the majority of previous studies. This could be because they included those cases in which an atypical variant did not exist in the entire cerebral arterial circle (anterior and posterior circulation). Moreover, although 3D TOF MRA allows in vivo visualization of the vasculature, its sensitivity depends on the speed of blood flow in the vessels making visualization of small vessels with low or turbulent blood flow difficult (Zhang et al.). The literature suggests that CTA represents the ideal radiologic method for the evaluation of the cerebral arterial circle and its collaterals ( $\mathrm{Li}$ et al.).

The presence of the azygos artery or a fenestration variant of the anterior cerebral artery or anterior communicating artery have been associated with the presence of aneurysms due to the turbulent flow created by defects in the tunica media in the proximal and distal region of the fenestrated segment (Boleaga-Durán et al.; Dimmick \& Faulder). In our study, an aneurysm associated with the azygos variant but not with a fenestration of the ACA or AComA was found. Previous morphological studies using imaging techniques reported prevalence between 0.24 and $1.50 \%$ of the azygos variant, while in cadaveric studies the range was $2-3.33 \%$, very similar data. Our study supports and extends the results reported by previous studies. Knowledge of the prevalence of the azygos variant is relevant because in an occlusive event of the ACA due to thromboembolic disease or during surgical procedures, ischemia of the medial aspect of both cerebral hemispheres occurs.

The presence of an occlusive event in a dominant A2 segment of the anterior cerebral artery when a hypoplasia variant exists in the contralateral A2 segment increases the risk of regional ischemia in both hemispheres (Kayembe et al.; Dimmick \& Faulder). Perlmutter \& Rhoton (1978) found a prevalence of $2-7 \%$ of the hypoplasia variant of the A2 segment in United States population, a figure that shows similarity with the results obtained in our study of $4.24 \%$. In the literature reviewed, there are few reports that have evaluated this arterial segment. Other variants that increase the risk of stroke due to decreased collateral blood flow during occlusive events are the variants absence and hypoplasia of the A1 segment of the anterior cerebral artery. Previous cadaveric studies do not report data on the absence variant of A1 but report a prevalence of $0-16 \%$ of hypoplastic A1, while studies using imaging methods showed a prevalence of the A1 absence variant of 0-5.20 \% and an A1 hypoplasia of 4$17.6 \%$, with a very wide range, using CTA. Our results were within the ranges previously described with cadaveric and imaging techniques, showing a greater similarity with results from studies in Polish population (Klimek- Piotrowska et al.;
Krzyz ewski et al.). Because of this, we believe that CTA is an accurate technique for assessing the hypoplasia variant of the anterior cerebral artery.

The limitations of the study were that although the included patients did not present an apparent cerebral vascular pathology in the radiological images, we cannot assure that they were completely healthy. Moreover, since there are few studies using the same methodology, our results were compared with various techniques including 16-slice CTA, whose sensitivity and specificity vary with respect to the 64slice used by us, on the other hand the analysis of images studies are operator-dependent so it can limit our results.

This study showed a high prevalence of atypical anatomical variants in Mexican population, of which variants known to increase the risk of ischemic events were the most found (absence of the anterior communicating artery, absence and hypoplasia of the precommunicating A1 segment, hypoplasia of the postcommunicating A2 segment of the anterior cerebral artery and the azygos artery) (Rhoton; Dimmick \& Faulder). We believe that studies that perform morphometric measurements by computed tomography are needed to provide data to compare our measurements.

\section{CONCLUSIONS}

This is the first study to investigate the prevalence of anatomical variants in the anterior cerebral artery and the anterior communicating artery in Mexican population using 3D computed tomography. We found a high prevalence of "atypical" variants. Absence and hypoplasia variants of the A1 segment of the ACA were the most prevalent and should be taken into account since they increase the risk of stroke by decreased blood flow during occlusive thrombotic events or endovascular procedures. The results of this study confirm the difference in variants found between different ethnic groups.

FINANCIAL DISCLOSURE. This research did not receive any specific grant from funding agencies in the public, commercial, or not-for-profit sectors.

ACKNOWLEDGEMENTS. We sincerely thank Neri Alvarez-Villalobos, M.D. for his support in the statistical analysis, Miguel Arturo Villarreal Barron M.A. for his technology support, Jaime A. Cisneros Rios M.A. for his assistance in preparing the artwork material presented in this study and Sergio Lozano-Rodriguez, M.D. for his help in translating the manuscript. 
JIMÉNEZ-SOSA, M. S.; CANTU-GONZALEZ, J. R.; MORALES-AVALOS, R.; GARZA-CASTRO, O.; QUIROGA-GARZA, A.; PINALES-RAZO, R.; ELIZONDO-RIOJAS, G.; ELIZONDO-OMAÑA, R. E. \& GUZMÁN-LÓPEZ, S. Anatomical variants of anterior cerebral arterial circle. A study by multidetector computerized $3 \mathrm{~d}$ tomographic angiography. Int. J. Morphol., 35(3):1121-1128, 2017.

JIMÉNEZ-SOSA, M. S.; CANTU-GONZALEZ, J. R.; MORALESAVALOS, R.; GARZA-CASTRO, O.; QUIROGA-GARZA, A.; PINALES-RAZO, R.; ELIZONDO-RIOJAS, G.; ELIZO NDO-OMAÑA, R. E.1 \& GUZMÁN-LÓPEZ, S. Variantes anatómicas de la región anterior del circulo arterial cerebral. Estudio por angiotomografía computarizada $3 \mathrm{~d}$. Int. J. Morphol., 35(3):1121-1128, 2017.

RESUMEN: Una de las causas más frecuentes de accidente cerebrovascular es la ruptura de aneurismas cuyo abordaje requiere el conocimiento de las variantes anatómicas. El presente estudio tuvo como objetivo determinar la prevalencia de variantes anatómicas de la Arteria Cerebral Anterior (ACA) y la Arteria Comunicante Anterior (AComA) mediante angiotomografías computarizadas 3D (angioTAC 3D) de individuos mexicanos. Se realizó un estudio retrospectivo, observacional, transversal y descriptivo en el que se evaluaron angioTAC contrastados con reconstrucción 3D de 283 pacientes, sin considerar género ni edad, obtenidas durante un periodo de dos años a los que se les realizaron mediciones morfométricas en los vasos de interés. Se encontró al menos una variante "atípica" en un tercio de la población estudiada $(33,93 \%)$. La variante "atípica" más común fue la ausencia de AComA $(14,1 \%)$. Se encontró asociación significativa entre la variante hipoplásica del segmento A1 derecha y la hipoplasia de A1 izquierda y A2 derecha; mientras que la hipoplasia de A1 izquierda se asoció a la variante hipoplasia de A2 derecha, encontrándose mayor tendencia de aparición de aneurismas en función del menor diámetro del segmento A2 derecho de la ACA. Existe diferencia en la prevalencia de variantes anatómicas del complejo ACA-AComA en población mexicana con respecto a otras poblaciones. La variante típica constituye la forma más prevalente en la población estudiada. Sin embargo, la presencia de variantes atípicas representa una cifra importante que deberá tomarse en cuenta en procedimientos clínicos y quirúrgicos.

PALABRAS CLAVE: Arteria cerebral anterior; Variantes anatómicas; Arteria comunicante anterior; Polígono de Willis; Hemorragia subaracnoidea; Cirugía endovascular cerebral.

\section{REFERENCES}

Boleaga-Durán, B.; Ameller-Terrazas, S. \& Criales-Cortés, J. L. Variantes anatómicas del círculo arterial de la base craneal. An. Radiol. Mex., 3(4):23944, 2004.

Cirillo, M.; Scomazzoni, F.; Cirillo, L.; Cadioli, M.; Simionato, F.; Iadanza, A.; Kirchin, M.; Righi, C. \& Anzalone, N. Comparison of 3D TOF-MRA and 3D CE-MRA at 3T for imaging of intracranial aneurysms. Eur. J. Radiol., 82(12):e853-9, 2013.

De Silva, K. R.; Silva, R.; Gunasekera, W. S. \& Jayesekera, R. W. Prevalence of typical circle of Willis and the variation in the anterior communicating artery: A study of a Sri Lankan population. Ann. Indian Acad. Neurol., 12(3):157$61,2009$.

Dimmick, S. J. \& Faulder, K. C. Normal variants of the cerebral circulation at multidetector CT angiography. Radiographics, 29(4):1027-43, 2009.

Ferré, J. C.; Niederberger, E.; Morandi, X.; Raoult, H.; Carsin-Nicol, B. \& Gauvrit, J. Y. Anatomical variations of the anterior cerebral arterial circle visualized by multidetector computed tomography angiography: comparison with 3D rotational angiography. J. Neuroradiol., 40(2):112-20, 2013.

Han, A.; Yoon, D. Y.; Chang, S. K.; Lim, K. J.; Cho, B. M.; Shin, Y. C.; Kim, S. S. \& Kim, K. H. Accuracy of CT angiography in the assessment of the circle of Willis: comparison of volume-rendered images and digital subtraction angiography. Acta Radiol., 52(8):889-93, 2011.

Hashemi, S. M.; Mahmoodi, R. \& Amirjamshidi, A. Variations in the Anatomy of the Willis' circle: A 3-year cross-sectional study from Iran (2006-2009). Are the distributions of variations of circle of Willis different in different populations? Result of an anatomical study and review of literature. Surg. Neurol. Int., 4:65, 2013

Instituto Nacional de Estadística y Geografía (INEGI). Mortalidad. Información sobre el Volumen de las Defunciones Registradas en el País, así como Algu- nas Características por Edad y Sexo de los Fallecidos y las Principales Causas que Originan los Decesos. Aguascalientes, INEGI Instituto Nacional de Estadistica y Geografía, 2015. Disponible en: http://www.beta.inegi.org.mx/ temas/mortalidad/

Iqbal, S. A comprehensive study of the anatomical variations of the circle of willis in adult human brains. J. Clin. Diagn. Res., 7(11):2423-7, 2013.

Kardile, P. B.; Ughade, J. M.; Pandit, S. V. \& Ughade, M. N. Anatomical variations of anterior communicating artery. J. Clin. Diagn. Res., 7(12):2661-4, 2013.

Kayembe, K. N.; Sasahara, M. \& Hazama, F. Cerebral aneurysms and variations in the circle of Willis. Stroke, 15(5):846-50, 1984.

Kedia, S.; Daisy, S.; Mukherjee, K. K.; Salunke, P.; Srinivasa, R. \& Narain, M. $\mathrm{S}$. Microsurgical anatomy of the anterior cerebral artery in Indian cadavers. Neurol. India, 61(2):117-21, 2013.

Klimek-Piotrowska, W.; Kopec, M.; Kochana, M.; Krzyz'ewski, R. M.; Tomaszewski, K. A.; Brzegowy, P. \& Walocha, J. Configurations of the circle of Willis: a computed tomography angiography based study on a Polish population. Folia Morphol. (Warsz.), 72(4):293-9, 2013.

Kovac, J. D.; Stankovic, A.; Stankovic, D.; Kovac, B. \& Saranovic, D. Intracranial arterial variations: a comprehensive evaluation using CT angiography. Med. Sci. Monit., 20:420-7, 2014.

Krzyzewski, R. M.; Tomaszewski, K. A.; Kochana, M.; Kopec', M.; KlimekPiotrowska, W. \& Walocha, J. A. Anatomical variations of the anterior communicating artery complex: gender relationship. Surg. Radiol. Anat., 37(1):81-6, 2015

Li, Q.; Li, J.; Lv, F.; Li, K.; Luo, T. \& Xie, P. A multidetector CT angiography study of variations in the circle of Willis in a Chinese population. J. Clin. Neurosci., 18(3):379-83, 2011.

Lu, H. T.; Tan, H. Q.; Gu, B. X.; Wu-Wang \& Li, M. H. Risk factors for multiple intracranial aneurysms rupture: a retrospective study. Clin. Neurol. Neurosurg., 115(6):690-4, 2013

Makowicz, G.; Poniatowska, R. \& Lusawa, M. Variants of cerebral arteries anterior circulation. Pol. J. Radiol., 78(3):42-7, 2013.

Monroy-Sosa, A.; Pérez-Cruz, J. C.; Reyes-Soto, G.; Delgado-Hernández, C.; Macías-Duvignau, M. A. \& Delgado-Reyes, L. Importancia de la anatomía microquirúrgica del complejo A1-arteria comunicante anterior. Cir. Cir., 81(4):274-81, 2013

Perlmutter, D. \& Rhoton, A. L. Jr. Microsurgical anatomy of the distal anterior cerebral artery. J. Neurosurg., 49(2):204-28, 1978.

Rhoton, A. L. Jr. The supratentorial arteries. Neurosurgery, 51(4 Suppl.):S53$120,2002$.

Stojanovic, N.; Stefanovic, I.; Kostic, A.; Radisavejevic, M.; Stojanov, D. \& Petrovic, S. Analysis of the symmetric configuration of the circle of Willis in a series of autopsied corpses. Vojnosanit Pregl., 72(4):356-60, 2015.

World Health Organization (WHO). Causes of death. Estimates for 2000-2015. Geneva, World Health Organization, 2017. Available from: http:// apps.who.int/gho/data/node.main.GHECOD?lang=en

Yi, H.; Hwang, H. S.; Choi, J. W.; Shin, I. Y. \& Choi, I. Anatomic features and clinical outcomes of 48 distal anterior cerebral artery aneurysms. Neurosurg. Q., 26(3):194-9, 2016

Zhang, Q. R.; Zhang, X.; Wu, Q.; Shi, J. X.; Wang, H. D.; Hang, C. H.; Cheng, H. L. \& Liu, J. M. The impact of microsurgical clipping and endovascular coiling on the outcome of cerebral aneurysms in patients over 60 years of age. J. Clin. Neurosci., 19(8):1115-8, 2012.

Corresponding author:

Rodrigo E. Elizondo-Omaña

Anatomy Research Group

Departamento de Anatomía Humana

Universidad Autónoma de Nuevo León (UANL)

Falcultad de Medicina

Hospital Universitario Dr. José Eleuterio González

Francisco I. Madera y Aguirre Pequeño s/n Col. Mitras Centro Monterrey, Nuevo León - MÉXICO

Email:michellesjs@hotmail.com

Received:24-04-2017

Accepted:13-07-2017 